\title{
Low-temperature deposition process for black phosphate-selenide coatings
}

\author{
V. Kh. Aleshina, Assistant, Dept. "Innovative materials and corrosion protection"1, e-mail: aleshinavh@gmail.com \\ A. A. Abrashov, Cand. Eng., Associate Prof., Dept. "Innovative materials and corrosion protection"l, \\ e-mail:abr-aleksey@yandex.ru \\ N. S. Grigoryan, Cand. Chem., Associate Prof., Dept. "Innovative materials and corrosion protection"l, \\ e-mail:ngrig108@mail.ru \\ T. A. Vagramyan, Dr. Eng., Prof., Head of Dept. "Innovative materials and corrosion protection"l, \\ e-mail: vagramian.t.a@muctr.ru
}

\section{${ }^{1}$ Mendeleev University of Chemical Technology of Russia, Moscow, Russia}

\begin{abstract}
Oxide coatings are widely used as protective and decorative coatings on ferrous metals under non-harsh operating conditions. For protective and decorative oxidation, a chemical oxidation method is widely used using concentrated alkaline solutions $(600-800 \mathrm{~g} / 1 \mathrm{NaOH})$ operating at very high temperatures $\left(130-150{ }^{\circ} \mathrm{C}\right)$. The obvious disadvantages of the process are the high energy consumption, difficult working conditions, the aggressiveness of the solutions used and low protective ability of the coatings due to their high porosity. In addition, it is known that to harden the surfaces of machine parts in order to increase wear resistance, they are thermally laser treated. The surface hardening is the more effective, the higher the absorption coefficient of the treated surface. For laser heat treatment, high-temperature $\left(95-98^{\circ} \mathrm{C}\right.$ ) processes of applying black phosphate coatings with a high absorption coefficient $(0.8-0.9)$ are used. The disadvantages of these processes are also the instability of solutions and the irreproducibility of the results.

This work is about to the study of the process of formation of phosphate-selenide coatings on steel in order to replace high-temperature solutions of black oxidation and phosphating.

A low-temperature process has been developed for the deposition of black selenide-containing phosphate coatings on steel, corresponding to a point of 10 on a ten-point color scale, in a solution containing: $4-8 \mathrm{~g} / 1 \mathrm{Na}_{2} \mathrm{SeO}_{3}$; $1-4 \mathrm{~g} / 1 \mathrm{CuSO}_{4} \cdot 5 \mathrm{H}_{2} \mathrm{O} ; 0.5-5 \mathrm{~g} / 1 \mathrm{NaH}_{2} \mathrm{PO}_{4}$ and $0.25-2.5 \mathrm{~g} / 1 \mathrm{Na}_{2} \mathrm{HPO}_{4}\left(\left[\mathrm{NaH}_{2} \mathrm{PO}_{4}\right] /\left[\mathrm{Na}_{2} \mathrm{HPO}_{4}\right]\right.$ molar ratio is 2$)$; 5 min at $\mathrm{pH}=2-3, \mathrm{t}=18-25^{\circ} \mathrm{C}$.

Oiling the coatings in I-20A industrial oil for 2 min leads to an increase in the protective ability of the coatings according to Akimov from 1 to $25 \mathrm{~min}$.

Corrosion tests of coatings in a salt spray chamber in accordance with ASTM B117 have shown that oiled phosphate-selenide coatings have the greatest protective ability: the first spots of red corrosion appear after 20 hours of testing, while oxidized, oiled samples begin to corrode after 18 hours. After 100 hours of testing, the area of the oxidized sample affected by corrosion is $90 \%$, and the oiled phosphated sample is 50 .
\end{abstract}

Key words: Protective ability; conversion coatings; black coatings; low temperature blackening of steel; selenidecontaining phosphate coatings; passivation of steel.

DOI: 10.17580/cisisr.2021.02.17

\section{Introduction}

Oxide coatings, which can be obtained by thermal, thermochemical, chemical and electrochemical methods, are widely used as protective and decorative coatings on ferrous metals under non-harsh operating conditions. Each of them finds its own, the most appropriate area of application. For protective and decorative oxidation, the most widely used chemical oxidation method with the use of alkaline solutions containing 600-800 g/ $1 \mathrm{NaOH}$, which makes it possible to obtain black or dark blue coatings up to $3 \mu \mathrm{m}$ thick at temperatures of $130-150{ }^{\circ} \mathrm{C}$. The obvious disadvantages of the alkaline oxidation process are high energy consumption, difficult working conditions and aggressiveness of the solutions used. In addition, coatings formed in alkaline solutions are highly porous and therefore can be used as protective coatings only in light climatic conditions [1, 2].
A more environmentally friendly and energy efficient alternative to protective and decorative black oxide coatings could be black phosphate coatings formed in low-temperature solutions. The relevance of the development of a lowtemperature process for the deposition of black coatings is also due to the following fact. It is known that to harden the surfaces of machine parts, the durability of which is determined by their wear resistance, they are thermally laser treated. In this case, surface hardening is the more effective, the higher the absorption coefficient of the treated surface. Processes for applying black phosphate coatings with a high absorption coefficient (0.8-0.9) are being developed especially for laser heat treatment. Known black phosphating processes are also high-temperature $\left(95-98^{\circ} \mathrm{C}\right)$. They have not found wide practical application due to such disadvantages as the instability of solutions and the irreproducibility of the results $[3,4]$. 
This study is devoted to the development of a low-temperature black coating deposition process, which is an alternative to the high-temperature black oxidation and steel phosphating processes.

\section{Materials and methods}

When preparing phosphating solutions, reagents of "pure" and "chemically pure" qualifications and distilled water were used. As samples for the deposition of phosphate coatings, we used plates of cold-rolled steel 1008, which is widely used in the automotive industry and other industries.

The mass of phosphate layer $\left(\mathrm{m}_{\mathrm{ph}}\right)$ and the mass of stripped metal $\left(\mathrm{m}_{\mathrm{str}}\right)$ were determined by the gravimetric method according to GOST 9.402-2004 (point 5) [5].

For an accelerated assessment of the protective ability of phosphate coatings, the drop method was used using a solution based on copper sulfate, sodium chloride and hydrochloric acid - Akimov's reagent [6]. The criterion for assessing the quality of the coating was the time until the color of the control area under the drop changes from gray to red-brown.

Corrosion tests of phosphate coatings were carried out in an Ascott S120iP salt fog chamber in accordance with the international standard ASTM B117 [7], adopted in the automotive industry, and in accordance with GOST 9.401-2018 [8]. The method consists in cyclic alternation of exposure to an aggressive environment $(5 \% \mathrm{NaCl})$, tropical atmosphere and indoor conditions.

The XPS spectra were recorded using a special CLAM100 camera mounted on an Auger microscope HB100 (Vacuum Generators, GB). The pressure in the working chamber was maintained below $10^{-8}$ Torr. The $\mathrm{Al}$ anode $(1486.6 \mathrm{eV})$ with a power of $200 \mathrm{~W}$ was used as an X-ray source. The instrument was calibrated by XPS of Au $4 \mathrm{f} 7 / 2$ metal peaks $(\mathrm{Eb}=84.0 \mathrm{eV})$, $\mathrm{Cu} 2 \mathrm{p} 3 / 2(\mathrm{~Eb}=932.5 \mathrm{eV})$. The pass energy of analyzer was set at $50 \mathrm{eV}$.

According to the results of the study were obtained survey spectra of coatings, which were decomposed into the constituent spectra of the elements after subtracting the background $[9,10]$.

\section{Experimental results and their discussion}

Taking into account the literature data, initially for the formation black protective and decorative coatings a solution containing sodium selenite $\mathrm{Na}_{2} \mathrm{SeO}_{3}$ and copper sulfate $\mathrm{CuSO}_{4} \cdot 5 \mathrm{H}_{2} \mathrm{O}$ was prepared. The influence of the concentration of the solution components on the appearance and protective ability of the forming coatings at a solution with $\mathrm{pH}=2.5$ and a temperature of $22^{\circ} \mathrm{C}$ was investigated.

The experiments carried out made it possible to determine the concentration range of the solution components, in which it is possible to obtain homogeneous continuous coatings: $4-8 \mathrm{~g} / 1 \mathrm{Na}_{2} \mathrm{SeO}_{3}$ and $2-5 \mathrm{~g} / 1 \mathrm{CuSO}_{4} \cdot 5 \mathrm{H}_{2} \mathrm{O}-$ it is surrounded by a black frame in the diagram (Fig. 1).

Outside these ranges, the quality of coatings is degraded. At lower concentrations of selenite ions and copper ions in

\begin{tabular}{|c|c|c|c|c|c|c|c|}
\hline & \multicolumn{6}{|c|}{ Concentration $\mathrm{Na}_{2} \mathrm{SeO}_{3}, \mathrm{~g} / \mathrm{l}$} \\
\hline & & 2 & 4 & 5 & 6 & 8 & 10 \\
\hline \multirow{7}{*}{ 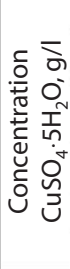 } & 1 & 5 & 6 & 7 & 7 & 7 & 7 \\
\hline & 2 & 7 & 8 & 9 & 10 & 10 & 7 \\
\hline & 3 & 7 & 8 & 9 & 10 & 10 & 7 \\
\hline & 4 & 8 & 9 & 10 & 10 & 10 & 6 \\
\hline & 5 & 8 & 9 & 10 & 10 & 10 & 6 \\
\hline & 6 & 6 & 7 & 7 & 7 & 6 & 5 \\
\hline & 7 & 5 & 5 & 5 & 5 & 4 & 4 \\
\hline
\end{tabular}

\begin{tabular}{|l|l|l|l|l|l|l|l|l|l|}
\hline \multicolumn{7}{|l|}{ Good quality black coatings } \\
\hline \multicolumn{7}{|l|}{ Satisfactory black coatings } \\
\hline \multicolumn{10}{|l|}{ Poor quality black coatings } \\
\hline 1 & 2 & 3 & 4 & 5 & 6 & 7 & 8 & 9 & 10 \\
\hline
\end{tabular}

Fig. 1. Dependence of the appearance of coatings from concentration $\mathrm{Na}_{2} \mathrm{SeO}_{3}$ and $\mathrm{CuSO}_{4} \cdot 5 \mathrm{H}_{2} \mathrm{O}$ on a ten-point color scale ( $\left.\mathrm{pH}=2-3 ; \mathrm{t}=22{ }^{\circ} \mathrm{C} ; \tau=5 \mathrm{~min}\right)$

solution, apparently, formed in the process of conversion of copper and iron selenides, which provide the black color of the coatings, are still insufficient. At high concentrations of selenite ions in the solution, most likely, the etching of the base increases, which leads to a decrease in the compactness of the coatings, and at high concentrations of copper ions in the solution, apparently, the quality of the coating is negatively affected by its contact release on the steel base.

The protective ability according to Akimov (PAA) of coatings formed under these conditions is $15-21 \mathrm{sec}$, and the color of the formed coatings corresponds to a score of $8-10$ on a ten-point black scale (Fig. 1).

Studies have shown that the permissible $\mathrm{pH}$ values of solutions are in the range of 2-3 units. $\mathrm{Up}$ to $\mathrm{pH} 2$, coatings are not formed, and at $\mathrm{pH}$ more than 3 units, the quality of coatings deteriorates - they become discontinuous.

It should be noted that the coatings formed even in the selected area of concentrations were solid, homogeneous and deep black, but they were all smeared.

Taking into account the literature recommendations, the possibility of eliminating this defect by introducing nickel or zinc ions into the solution was investigated. It was found that the introduction of $0.8-1.6 \mathrm{~g} / \mathrm{l}$ of $\mathrm{Zn}^{2+}$ or $\mathrm{Ni}^{2+}$ ions into the solution increases the protective ability of the resulting coatings from 20 to $38 \mathrm{sec}$, however, the desired effect on the compactness of the coatings is not achieved, in addition, the black color of the coatings is lost - point color decreases from 10 to 8 .

The possibility of improving the quality of coatings by introducing nitrate ions into the solution has been investigated. It was found that the introduction of $6-12 \mathrm{~g} / \mathrm{l}$ of sodium nitrate into the solution makes it possible to improve the compactness of the coatings and increase their protective ability, however, the color of the coatings in this case changes from black to dark gray. Despite the improvement in the quality and increase in the protective ability of the forming coatings, it was necessary to abandon the introduction of these additives because of the color of the coatings. 
The possibility of achieving the required characteristics of the coating was also tested by introducing into the solution such compounds as m-NBS, hydroxylamine sulfate, and ammonium molybdate. There were no positive effects from the introduction of these substances; moreover, in all cases, the protective ability decreased and the appearance of the coatings deteriorated.

It was possible to improve the quality of the coatings without losing their black color by introducing sodium salts of phosphoric acid $\mathrm{Na}_{2} \mathrm{HPO}_{4}, \mathrm{NaH}_{2} \mathrm{PO}_{4}$ or $\mathrm{Na}_{3} \mathrm{PO}_{4}$ into the solution.

The influence of the concentration of phosphates on the quality and protective characteristics of the obtained coatings was investigated (Fig. 2). It was found that the introduction of $\mathrm{Na}_{3} \mathrm{PO}_{4}$ into the working solution practically does not affect the characteristics of the layers. The presence of $\mathrm{NaH}_{2} \mathrm{PO}_{4}$ or $\mathrm{Na}_{2} \mathrm{HPO}_{4}$ in the solution leads to an increase in the protective ability of the forming layers. The introduction of $2-3 \mathrm{~g} / 1$ $\mathrm{NaH}_{2} \mathrm{PO}_{4}$ or $1-3 \mathrm{~g} / 1 \mathrm{Na}_{2} \mathrm{HPO}_{4}$ into the solution leads to an increase in the protective ability from 20 to 40 and $33 \mathrm{sec}$, respectively.

The effect of the concentration of phosphates on the quality and protective characteristics of the coatings has been studied when they are present together in the working solution. It was found that coatings of good quality with maximum protective ability are formed when the $\mathrm{NaH}_{2} \mathrm{PO}_{4} /$ $\mathrm{Na}_{2} \mathrm{HPO}_{4}$ ratio is $2 / 1$ (Fig. 3).

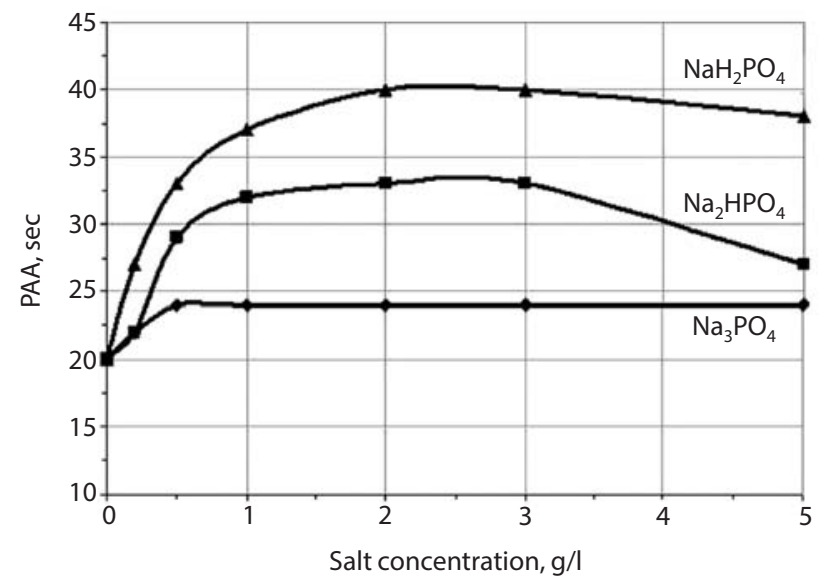

Fig. 2. Effect of phosphate concentration on the protective ability of coatings

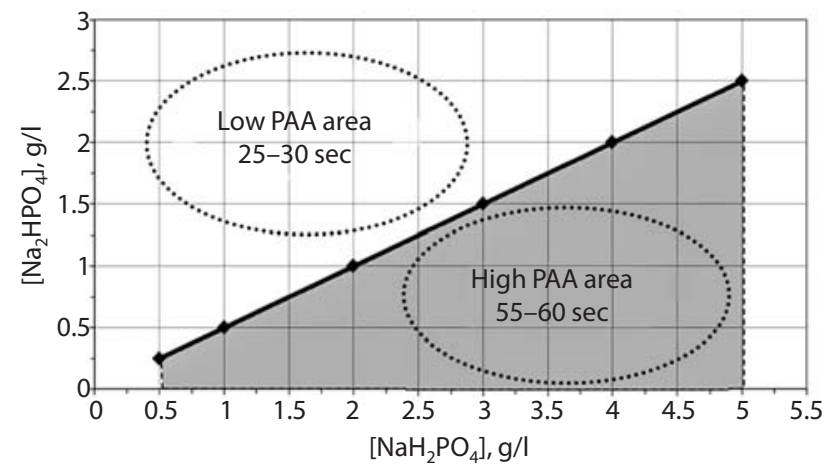

Fig. 3. Dependence of the protective ability of coatings on the ratio $\left[\mathrm{NaH}_{2} \mathrm{PO}_{4}\right] /\left[\mathrm{Na}_{2} \mathrm{HPO}_{4}\right]$
So, for example, a solution containing $0.5-5.0 \mathrm{~g} / 1$ $\mathrm{NaH}_{2} \mathrm{PO}_{4}$ and $0.25-2.5 \mathrm{~g} / 1 \quad \mathrm{Na}_{2} \mathrm{HPO}_{4} \quad\left(\left[\mathrm{NaH}_{2} \mathrm{PO}_{4}\right] /\right.$ $\left[\mathrm{Na}_{2} \mathrm{HPO}_{4}\right]=2$ ) allows you to obtain compact, smearfree coatings of deep black colors with a protective ability of 55-60 sec. Outside the limits of this range, the PAA decreases to $25-30 \mathrm{sec}$.

Thus, the developed solution containing: 4-8 g/1 $\mathrm{Na}_{2} \mathrm{SeO}_{3} ; 1-4 \mathrm{~g} / 1 \mathrm{CuSO}_{4} \cdot 5 \mathrm{H}_{2} \mathrm{O} ; 0,5-5 \mathrm{~g} / 1 \quad \mathrm{NaH}_{2} \mathrm{PO}_{4}$ and $0,25-2,5 \mathrm{~g} / 1 \mathrm{Na}_{2} \mathrm{HPO}_{4}\left(\left[\mathrm{NaH}_{2} \mathrm{PO}_{4}\right] /\left[\mathrm{Na}_{2} \mathrm{HPO}_{4}\right]=2\right)$; $\mathrm{pH}=2-3, \mathrm{t}=18-25^{\circ} \mathrm{C}$.

It can be assumed that the process of formation of phosphate-selenide coatings in the developed solution is described by the reactions:

$$
\begin{aligned}
& \mathrm{Fe}+4 \mathrm{NaH}_{2} \mathrm{PO}_{4} \rightarrow \mathrm{Fe}\left(\mathrm{H}_{2} \mathrm{PO}_{4}\right)_{2}+2 \mathrm{Na}_{2} \mathrm{HPO}_{4}+\mathrm{H}_{2} \\
& 2 \mathrm{Fe}\left(\mathrm{H}_{2} \mathrm{PO}_{4}\right)_{2}+2 \mathrm{Na}_{2} \mathrm{HPO}_{4}+0.5 \mathrm{O}_{2} \rightarrow 2 \mathrm{FePO}_{4}+ \\
& +4 \mathrm{NaH}_{2} \mathrm{PO}_{4}+\mathrm{H}_{2} \mathrm{O} \\
& 3 \mathrm{Fe}+\mathrm{SeO}_{3}^{2-}+6 \mathrm{H}^{+} \rightarrow 3 \mathrm{Fe}^{2+}+\mathrm{Se}^{2-}+3 \mathrm{H}_{2} \mathrm{O} \\
& \mathrm{Cu}^{2+}+\mathrm{Se}^{2-} \rightarrow \mathrm{CuSe} \\
& \mathrm{Cu}^{2+}+\mathrm{Fe} \rightarrow \mathrm{Fe}^{2+}+\mathrm{Cu} \\
& \mathrm{Fe}^{2+}+\mathrm{Se}^{2-} \rightarrow \mathrm{FeSe}
\end{aligned}
$$

Taking into account the above reactions, the forming coating should, probably, along with iron phosphates, also contain copper and iron selenides: CuSe and FeSe. X-ray phase studies have shown that the composition of the coatings, indeed, includes FeSe, $\mathrm{CuSe}, \mathrm{FePO}_{4}$ (Table).

The criterion for the completion of the conversion coating formation process is the stabilization of the mass

\begin{tabular}{|c|c|c|c|c|}
\hline \multicolumn{5}{|c|}{ Coating composition } \\
\hline Component & $\begin{array}{c}\text { Line } \\
\text { Designation }\end{array}$ & $\begin{array}{c}\text { Binding } \\
\text { Energy }(\mathrm{eV})\end{array}$ & $\begin{array}{l}\text { Literary } \\
\text { source }\end{array}$ & $\begin{array}{l}\text { Quantitative } \\
\text { composition, } \\
\text { at.\% }\end{array}$ \\
\hline \multirow{2}{*}{ FeSe } & $\mathrm{Fe} 2 \mathrm{p}$ & 710.9 & \multirow{2}{*}{ [11] } & \multirow{2}{*}{33} \\
\hline & Se 3d & 54.75 & & \\
\hline \multirow{2}{*}{ CuSe } & $\mathrm{Cu} 2 \mathrm{p}_{3 / 2}$ & 934.85 & \multirow{2}{*}{ [12] } & \multirow{2}{*}{38} \\
\hline & Se 3d & 54.75 & & \\
\hline \multirow{3}{*}{$\mathrm{FePO}_{4}$} & $\mathrm{Fe} 2 \mathrm{p}_{3 / 2}$ & 712.80 & [13] & \multirow{3}{*}{16} \\
\hline & $\mathrm{P} 1 \mathrm{~s}$ & 2148.15 & [14] & \\
\hline & $\mathrm{P} 2 \mathrm{~s}$ & 192.52 & [15] & \\
\hline
\end{tabular}
of the phosphate layer during the process. As can be seen from the presented kinetic curve, the formation of the coating in the developed solution is completed within 8 min (Fig. 4).

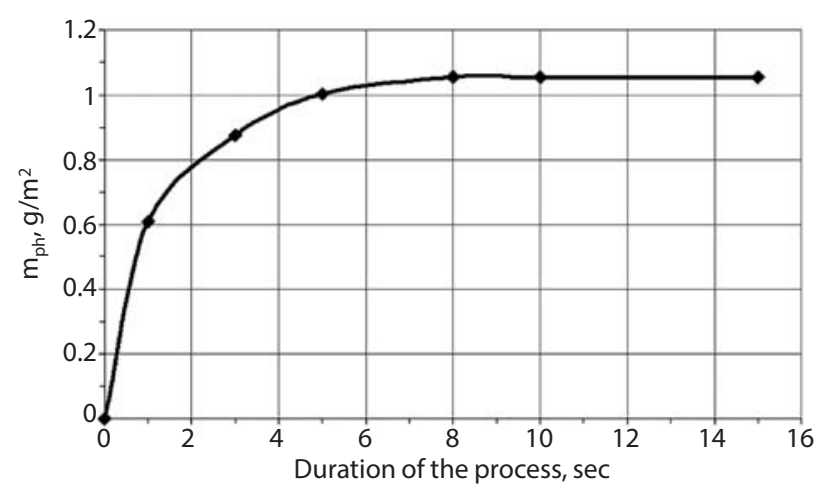

Fig. 4. Change in $\mathrm{m}_{\mathrm{ph}}$ during coating 


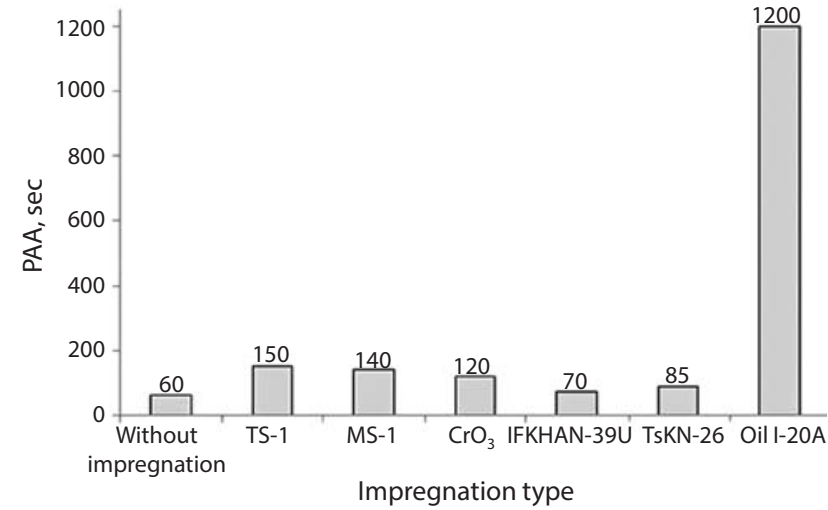

Fig. 5. Influence of the nature of the impregnating composition on the protective ability of coatings

It is known that to increase the protective ability of conversion coatings, they are finished with the purpose of additional protection in the form of organic or inorganic thin films ("top-coat") or impregnating compositions ("sealer").

IFKHAN-39U (mixture of carboxylate type corrosion inhibitors), TsKN-26 (water-soluble polymer composition based on styrene and acrylic acid), $\mathrm{CrO}_{3}, \mathrm{TS}-1$ (organic additive based on gallic acid compounds) and MS-1 (inorganic additive based on sodium metasilicate), as well as technical oil I-20A, were tested as impregnating compositions. The selenide-phosphate layers treated with I-20A oil have the greatest protective ability (Fig. 5).

It was also found that the impregnation of black phosphate-selenide coatings in industrial oil for 1 min leads to an increase in the protective ability from 1 to $20 \mathrm{~min}$. With an increase in the duration of soaking in oil to $2 \mathrm{~min}$, the protective ability increases to $25 \mathrm{~min}$. It should be noted that the color of the coatings after oiling becomes deeper and more saturated.

Experiments have shown that the protective ability according to Akimov of oiled phosphate-selenide coatings is slightly higher than the protective ability of oiled oxide layers obtained from a standard alkaline solution of chemical oxidation: $25 \mathrm{~min}$ versus $21 \mathrm{~min}$, respectively.

Corrosion testing of coatings in a salt spray chamber was carried out in accordance with ASTM B117. Tests have shown that oiled phosphate-selenide coatings have the greatest protective ability: the first spots of red corrosion appear after 20 hours of testing, while oxidized, oiled samples begin to corrode after 18 hours. After 100 hours of testing, the area of the oxidized sample affected by corrosion is $90 \%$, and the oiled phosphated sample is $50 \%$.

\section{Conclusions}

1. A low-temperature process has been developed for applying black phosphate-selenide coatings on steel in a solution containing: $4-8 \mathrm{~g} / 1 \mathrm{Na}_{2} \mathrm{SeO}_{3} ; 1-4 \mathrm{~g} / 1 \mathrm{CuSO}_{4} \cdot 5 \mathrm{H}_{2} \mathrm{O}$; $0.5-5 \mathrm{~g} / 1 \mathrm{NaH}_{2} \mathrm{PO}_{4}$ and $0.25-2.5 \mathrm{~g} / 1 \mathrm{Na}_{2} \mathrm{HPO}_{4}$ (molar ratio $\left.\left[\mathrm{NaH}_{2} \mathrm{PO}_{4}\right] /\left[\mathrm{Na}_{2} \mathrm{HPO}_{4}\right]=2\right) ; \mathrm{pH}=2-3, \mathrm{t}=18-25^{\circ} \mathrm{C}$.

2. It was found that copper and iron selenides are included in the composition of conversion phosphate-selenide coatings: $33 \% \mathrm{FeSe}, 38 \% \mathrm{CuSe}$ and $16 \% \mathrm{FePO}_{4}$.
3. It was found that the impregnation of black phosphateselenide coatings in industrial oil leads to an increase in the protective ability according to Akimov from 1 to 25 minutes, and the color of the coatings becomes deeper and more saturated.

4. Corrosion tests of coatings in a salt spray chamber in accordance with ASTM B117 showed that oiled phosphateselenide coatings have the greatest protective ability: the first spots of red corrosion appear after 20 hours of testing, while oxidized oiled samples begin to corrode after 18 hours. After 100 hours of testing, the area of the oxidized sample affected by corrosion is $90 \%$, and the oiled phosphated sample is $50 \%$.

5. The developed coatings can serve as an alternative to high-temperature protective and decorative black oxide and phosphate coatings on steel.

The work was carried out with the financial support of the Mendeleev University of Chemical Technology. Project number $X$-2020-027.

\section{REFERENCES}

1. Somrerk Chandra-ambhorn, Sermsak Srihirun, Thamrongsin Siripongsakul. Effects of blackening parameters on the formation and adhesion of oxide on AISI 4140 steel. Anti-Corrosion Methods and Materials. 2018. Vol. 65. No. 4. pp. 383-388.

2. Eckl M., Zaubitzer S., Köntje C., Farkas A., Kibler L. A., Jacob T. An Electrochemical Route for Hot Alkaline Blackening of Steel: A Nitrite Free Approach. Surfaces. 2019. Vol. 2. No. 2. pp. 216-228.

3. Grigoryan N. S., Akimova E. F., Vagramyan T. A. Phosphating: textbook. M.: Globus, 2008. 144 p.

4. Feng Li, Guiping Wang. A Black Phosphate Conversion Coating on Steel Surface Using Antimony(III)-Tartrate as an Additive. Journal of Materials Engineering and Performance. 2016. Vol. 25. No. 5. pp. $1864-1869$.

5. GOST 9.402-2004. Paint coatings. Metal surface preparation for painting. 2006. $95 \mathrm{p}$.

6. Abrashov A. A., Grigoryan N. S., Vagramyan T. A., Asnis N. A. On the Mechanism of Formation of Conversion Titanium-Containing Coatings. Coatings. 2020. Vol. 10. No. 4. pp. 328-339.

7. ASTM B117-11. Standard Practice for Operating Salt Spray (Fog) Apparatus. 2011. $12 \mathrm{p}$.

8. GOST 9.401-2018. Unified system of corrosion and ageing protection. Paint coatings. General requirements and methods of accelerated tests on resistance to the action of climatic factors. 2018. 105 p.

9. Woicik J. C. Hard X-ray Photoelectron Spectroscopy (HAXPES). Springer International Publishing Switzerland. 2016. 571 p.

10. Shcherbina E. A., Abrashov A. A., Grigoryan N. S., Vagramyan T. A., Men'shikov V. V. Black Ni-based galvanic coatings. METAL 201928th International Conference on Metallurgy and Materials, Conference Proceedings, 2019. Vol. 28. pp. 1140-1144.

11. Shenasa M., Sainkar S., Lichtman D. XPS study of some selected selenium compounds. Journal of Electron Spectroscopy and Related Phenomena. 1986. Vol. 40. Mo. 4. pp. 329-333.

12. Yong Zhang, Zheng-Ping Qiao, Xiao-Ming Chen. Microwaveassisted elemental direct reaction route to nanocrystalline copper chalcogenides CuSe and $\mathrm{Cu}_{2} \mathrm{Te}$. Journal of Materials Chemistry. 2002. Vol. 12. pp. 2747-2748

13. Bardhan A., Ghosh C. K., Mitra M. K., Das G. C., Mukherjee S., Chattopadhyay K. K. Low temperature synthesis of zinc ferrite nanoparticles. Solid State Sciences, 2010. Vol. 12. No. 5. pp. 839-844.

14. Franke R., Chasse Th., Streubel P., Meisel A. Auger parameters and relaxation energies of phosphorus in solid compounds. Journal of Electron Spectroscopy and Related Phenomena, 1991. Vol. 56. No. 4. pp. 381-388.

15. Yuqing Wang, Sherwood P. M. A. Iron (III) Phosphate $\left(\mathrm{FePO}_{4}\right)$ by XPS. Surface Science Spectra. 2002. Vol. 9. pp. 99-105. 